\title{
Sonnien sosiaalinen käyttäytyminen erikokoisissa ryhmissä
}

\author{
Leena Tuomisto $^{1)}$, Minna Lyyra $^{2)}$ ja Arto Huuskonen ${ }^{3)}$ \\ ${ }^{1)}$ Maa- ja elintarviketalouden tutkimuskeskus, Kotieläintuotannon tutkimus, Halolantie 31 A, 71750 \\ Maaninka,leena.tuomisto@mtt.fi \\ ${ }^{2)}$ Itä-Suomen yliopisto, Biotieteiden laitos, PL 1627, 70211 Kuopio, mlyyra@student.uef.fi \\ ${ }^{3)}$ Maa- ja elintarviketalouden tutkimuskeskus, Kotieläintuotannon tutkimus, Tutkimusasemantie 15, \\ 92400 Ruukki, arto.huuskonen@mtt.fi
}

\section{Tiivistelmä}

Lihanautojen loppukasvatuksessa sonnit pidetään tyypillisesti lämpimissä rakennuksissa rakolattiapohjaisissa karsinoissa. Pienellä ryhmäkoolla ja uudelleenryhmittelyn välttämisellä tavoitellaan sosiaalisesti vakaata ryhmää. Joillakin tiloilla on kuitenkin saatu hyviä tuloksia sonnien kasvattamisesta tavallista suuremmissa ryhmissä. Tutkimuksen tarkoituksena oli selvittää loppukasvatettavien sonnien sosiaalista käyttäytymistä keskisuurissa ja suurissa eläinryhmissä. Tutkimus toteutettiin tilatutkimuksena lihanautojen loppukasvatustiloilla. Tutkimuksessa oli mukana kaksi tilaa, joilla sonnit kasvatettiin keskisuurissa ryhmissä (32-40 sonnia/ryhmä) osittain tai kokonaan rakolattiapohjaisissa karsinoissa (tilaa 3,0-3,7 m²/eläin) sekä kolme tilaa, joilla sonnit kasvatettiin suurissa ryhmissä (130-237 sonnia/ryhmä) eristämättömissä pihatoissa tai tarhassa, jossa oli katettu makuualue (tilaa 4,4-8,8 $\mathrm{m}^{2} /$ eläin). Yhteensä tutkittavia sonniryhmiä oli kymmenen. Sonneja tarkkailtiin joka tilalla suoralla seurannalla kahtena peräkkäisenä päivänä klo 6:00-20:00 välisenä aikana. Eläinten yleisen aktiivisuuden selvittämiseksi käytettiin hetkellistä seurantaa 15 minuutin havaintovälillä. Hetkellisen seurannan havaintopisteiden välissä laskettiin erityyppisten sosiaalisten kontaktien määrä käyttäen yksi-nolla seurantaa. Tutkimustiloillamme sonniryhmän koolla ei näyttänyt olevan vaikutusta tappelujen, muussa kuin ruokailutilanteessa tapahtuvan puskemisen ja syrjäyttämisen tai makuulta ylös ajamisen osuuksiin kaikista sosiaalisista kontakteista. Vain yhdessä suuressa ryhmässä kiinteäpohjaisessa karsinassa nujuamisen ja leikkitappelun osuus kaikista kontakteista oli selkeästi suurempi kuin keskisuurissa ryhmissä rakolattiakarsinoissa. Tutkimustiloillamme oli havaittavissa suuntaus, että ruokailutilanteessa tapahtuvan puskemisen ja syrjäytysten sekä sosiaalisen nuolemisen osuus kaikista kontakteista oli suurempi keskisuurissa rakolattiakarsinoiden ryhmissä kuin suurissa ryhmissä kiinteäpohjaisissa karsinoissa. Lisäksi suuntauksena oli, että toisen eläimen selkään hyppäämisen osuus kaikista kontakteista oli suurempi suurissa kiinteäpohjaisten karsinoiden ryhmissä kuin keskisuurissa ryhmissä rakolattiakarsinoissa, joskin suurissa ryhmissä hajonta oli huomattavaa. Tilatutkimuksessamme emme havainneet, että aggressiivisen käyttäytymisen osuus kaikista sosiaalisista kontakteista olisi suurempi suurissa sonniryhmissä kiinteäpohjaisissa karsinoissa kuin keskisuurissa sonniryhmissä rakolattiakarsinoissa. Suhteellisen alhainen eläintiheys saattoi hillitä aggressiivista käyttäytymistä suurissa ryhmissä. Sosiaalisen nuolemisen suurempi osuus kaikista kontakteista keskisuurissa ryhmissä voi merkitä sitä, että pienemmissä ryhmissä eläimet pystyivät muodostamaan kiinteämpiä suhteita toisiinsa. Tutkimuksemme aineisto oli hyvin pieni ja tulokset kuvailevia, joten johtopäätösten luotettavuuteen ja tulosten yleistettävyyteen on suhtauduttava varauksella.

Asiasanat: naudanlihantuotanto, sonnit, ryhmäkoko, sosiaalinen käyttäytyminen 


\section{Johdanto}

Lihanautojen loppukasvatuksessa sonnit pidetään tyypillisesti lämpimissä rakennuksissa rakolattiapohjaisissa karsinoissa. Eläintiheys näissä karsinoissa on usein korkea. Sonnit pyritään kasvattamaan samoissa, korkeintaan 20 eläimen ryhmissä koko loppukasvatuksen ajan. Pienellä ryhmäkoolla ja uudelleenryhmittelyn välttämisellä tavoitellaan sosiaalisesti vakaata ryhmää, jossa levoton ja aggressiivinen käyttäytyminen pysyvät kurissa. Joillakin tiloilla on kuitenkin saatu hyviä tuloksia sonnien kasvattamisesta tavallista suuremmissa ryhmissä. Keskisuurien ja suurien ryhmien vaikutuksesta sonnien käyttäytymiseen ja hyvinvointiin on kuitenkin hyvin vähän tutkimustietoa. Tämän tutkimuksen tarkoituksena oli selvittää loppukasvatettavien sonnien sosiaalista käyttäytymistä keskisuurissa ja suurissa eläinryhmissä.

\section{Aineisto ja menetelmät}

Tutkimus toteutettiin tilatutkimuksena kesällä 2010 lihanautojen loppukasvatustiloilla. Tutkimuksessa oli mukana kaksi tilaa, joilla sonnit kasvatettiin keskisuurissa ryhmissä (32-40 sonnia/ryhmä) sekä kolme tilaa, joilla sonnit kasvatettiin suurissa ryhmissä (130-237 sonnia/ryhmä) (Taulukko 1). Yhteensä tutkittavia sonniryhmiä oli kymmenen. Eläintä kohden tilaa oli keskisuurissa ryhmissä 3,0-3,7 $\mathrm{m}^{2}$ ja suurissa ryhmissä 4,4-8,8 $\mathrm{m}^{2}$. Keskisuuret ryhmät kasvatettiin eristetyissä kasvattamoissa osittain tai kokonaan rakolattiapohjaisissa karsinoissa. Suuret ryhmät kasvatettiin eristämättömissä pihatoissa tai betonipohjaisessa tarhassa, jossa oli katettu makuualue. Eristämättömissä pihatoissa kuivikkeena käytettiin turvetta. Sonniryhmät koostuivat suurin piirtein saman ikäisistä (10-18 kk) eläimistä. Muista tiloista poiketen tilalla 4 karsina oli jatkuvatäyttöinen. Tilan 4 jatkuvatäyttöinen karsina toimi siten, että vanhimpien ja suurimpien eläinten lähtiessä teuraaksi niiden tilalle tuotiin nuoria eläimiä. Tarkkailujen aikana tilan 4 sonniryhmän nuorimmat eläimet olivat kuuden kuukauden ikäisiä ja vanhimmat yli kaksivuotiaita.

Jokaisella tilalla tehtiin tarkkailuja kahtena peräkkäisenä päivänä klo 6:00-20:00 välisenä aikana, jolloin tarkkailua kertyi yhteensä 28 tuntia eläinryhmää kohden. Tilan 4 käyttäytymistulokset esitetään kuitenkin vain toiselta tarkkailupäivältä, koska ensimmäisenä tarkkailupäivänä tarkkailut epäonnistuivat epävakaan sään vuoksi. Käyttäytymistarkkailut tehtiin suoralla seurannalla. Keskisuurissa ryhmissä tarkkailua teki kaksi tarkkailijaa (yksi tarkkailija kerrallaan) ja suurissa ryhmissä neljä tarkkailijaa (kaksi tarkkailijaa kerrallaan). Tarkkailijat vuorottelivat kahden tunnin jaksoissa. Tarkkailua helpottamaan suurien ryhmien karsinat jaettiin 3-6 pienempään osaan.

Käyttäytymishavaintojen keräämisessä käytettiin hetkellistä seurantaa 15 minuutin havaintovälillä ja yksi-nolla seurantaa hetkellisen seurannan havaintopisteiden välissä (Martin ja Bateson 1993). Hetkellisen seurannan havaintopisteissä laskettiin makaavien, syövien, juovien ja seisovien eläinten määrä karsinoissa tai karsinan osissa. Yksi-nolla seurannalla laskettiin erityyppisten sosiaalisten kontaktien määrä taulukossa 2 esitetyn luokittelun mukaan. Kullakin yksi-nolla seurannan jaksolla kukin tarkkailija tarkkaili vain yhtä karsinaa (keskisuuret ryhmät) tai karsinan osaa (suuret ryhmät). Tarkkailtavaa karsinaa tai karsinan osaa vaihdettiin jokaisella yksi-nolla seurannan jaksolla. Tulokset esitetään kuvailevina. Suurien ryhmien karsinoiden eri osista tehdyt havainnot yhdistettiin ryhmäkohtaisiksi havainnoiksi. Koska eläinryhmien välillä oli vaihtelua yleisessä aktiivisuudessa, erityyppisiä sosiaalisia kontakteja tarkastellaan suhteellisina osuuksina kaikista sosiaalisista kontakteista.

\section{Tulokset ja tulosten tarkastelu}

Nautojen on arvioitu pystyvän tunnistamaan 50-70 lajitoveriaan (Fraser ja Broom 2002). Lajitoverien tunnistaminen on oleellista dominanssihierarkian vakauden kannalta. Kun eläimet tunnistavat toisensa yksilöllisesti, ne pystyvät muistamaan oman asemansa lauman hierarkiassa suhteessa muiden lauman jäsenten asemaan. Suurissa ryhmissä toisten eläinten tunnistaminen vaikeutuu ja eläinten väliset aggressiiviset kohtaamiset lisääntyvät. Kondo ym. (1989) havaitsivatkin yli kaksivuotiailla hiehoilla, härillä ja lehmillä agonistisen käyttäytymisen (puskee, uhkailee, väistää) lisääntyvän ryhmäkoon (8-91 eläintä) suurentuessa. Tutkimustiloillamme ryhmäkoolla ei näyttänyt olevan vaikutusta tappelujen, muussa kuin ruokailutilanteessa esiintyvän puskemisen ja syrjäyttämisen tai makuulta ylös ajamisen osuuksiin kaikista sosiaalisista kontakteista (Kuvat 1, 2 ja 3). Kaiken kaikkiaan vakavia tappeluja esiintyi tutkimustiloillamme pääsääntöisesti hyvin harvoin. Nujuamisen ja leikkitappelun osuus kaikista kontakteista oli vain yhdessä suuressa ryhmässä selkeästi suurempi kuin keskisuurissa ryhmissä. 
Taulukko 1. Taustatiedot tutkimuksen eläinryhmistä ja kasvatusolosuhteista.

\begin{tabular}{|c|c|c|c|c|c|c|c|c|c|c|}
\hline $\begin{array}{l}\text { Ryhmän } \\
\text { koko, eläintä }\end{array}$ & 32 & 35 & 37 & 38 & 38 & 40 & 130 & 171 & 225 & 237 \\
\hline Tila & Tila 1 & Tila 1 & Tila 2 & Tila 2 & Tila 2 & Tila 2 & Tila 3 & Tila 3 & Tila 4 & Tila 5 \\
\hline Eläinten ikä & $14-15 \mathrm{kk}$ & $14-15 \mathrm{kk}$ & noin $18 \mathrm{kk}$ & noin $12 \mathrm{kk}$ & noin $14 \mathrm{kk}$ & noin $16 \mathrm{kk}$ & $13-15 \mathrm{kk}$ & $10-11 \mathrm{kk}$ & $\begin{array}{l}6 \mathrm{kk}- \\
\text { yli } 24 \mathrm{kk}\end{array}$ & noin $14 \mathrm{kk}$ \\
\hline $\begin{array}{l}\text { Vallitseva } \\
\text { rotu }\end{array}$ & Maitorodut & Maitorodut & Maitorodut & Maitorodut & Maitorodut & Maitorodut & Maitorodut & Maitorodut & Liharodut & Liharodut \\
\hline $\begin{array}{l}\text { Kasvattamo- } \\
\text { tyyppi }\end{array}$ & $\begin{array}{l}\text { Rakolattia } \\
\text { ja kiinteä } \\
\text { makuualue }\end{array}$ & $\begin{array}{l}\text { Rakolattia } \\
\text { ja kiinteä } \\
\text { makuualue }\end{array}$ & Rakolattia & Rakolattia & Rakolattia & Rakolattia & $\begin{array}{l}\text { Kylmä- } \\
\text { pihatto }\end{array}$ & $\begin{array}{l}\text { Kylmä- } \\
\text { pihatto }\end{array}$ & $\begin{array}{l}\text { Makuukatos } \\
\text { ja jaloittelu- } \\
\text { tarha }\end{array}$ & $\begin{array}{l}\text { Kylmä- } \\
\text { pihatto }\end{array}$ \\
\hline $\begin{array}{l}\text { Kokonais- } \\
\text { pinta-ala }\end{array}$ & $118 \mathrm{~m}^{2}$ & $118 \mathrm{~m}^{2}$ & $120 \mathrm{~m}^{2}$ & $120 \mathrm{~m}^{2}$ & $120 \mathrm{~m}^{2}$ & $120 \mathrm{~m}^{2}$ & $750 \mathrm{~m}^{2}$ & $750 \mathrm{~m}^{2}$ & $1980 \mathrm{~m}^{2}$ & $1200 \mathrm{~m}^{2}$ \\
\hline $\begin{array}{l}\text { Pinta-ala / } \\
\text { eläin }\end{array}$ & $3,7 \mathrm{~m}^{2}$ & $3,4 \mathrm{~m}^{2}$ & $3,2 \mathrm{~m}^{2}$ & $3,2 \mathrm{~m}^{2}$ & $3,2 \mathrm{~m}^{2}$ & $3,0 \mathrm{~m}^{2}$ & $5,8 \mathrm{~m}^{2}$ & $4,4 \mathrm{~m}^{2}$ & $8,8 \mathrm{~m}^{2}$ & $5,1 \mathrm{~m}^{2}$ \\
\hline $\begin{array}{l}\text { Ruokailu- } \\
\text { tilaa / eläin }\end{array}$ & $0,58 \mathrm{~m}$ & $0,53 \mathrm{~m}$ & $0,54 \mathrm{~m}$ & $0,53 \mathrm{~m}$ & $0,53 \mathrm{~m}$ & $0,50 \mathrm{~m}$ & $0,46 \mathrm{~m}$ & $0,35 \mathrm{~m}$ & $0,40 \mathrm{~m}$ & $0,25 \mathrm{~m}$ \\
\hline
\end{tabular}

Taulukko 2. Käyttäytymisseurannoissa havainnoidut toiminnot ja niiden kuvaukset.

\begin{tabular}{|l|l|}
\hline Toiminto & Kuvaus \\
\hline Nujuaa, leikkitappelee & Sonnit puskevat toisiaan otsallaan tai sarvillaan ilman vihamielistä tarkoitusta. \\
\hline Tappelee & $\begin{array}{l}\text { Kaksi sonnia työntää rajusti otsallaan tai sarvillaan toisiaan. Jalat ovat tukevasti maassa ja molemmat sonnit käyttävät puske- } \\
\text { miseen voimaa. }\end{array}$ \\
\hline Puskee ruokailutilanteessa & Sonni puskee tai työntää toista sonnia otsallaan tai sarvillaan ruokailutilanteessa. Kohdesonni ei väistä. \\
\hline Puskee muussa tilanteessa & Sonni puskee tai työntää toista sonnia otsallaan tai sarvillaan muussa kuin ruokailutilanteessa. Kohdesonni ei väistä. \\
\hline Syrjäyttää ruokailutilanteessa & Sonni pakottaa toisen sonnin luovuttamaan paikkansa ruokailutilanteessa puskemalla tai voimakkaalla vartalon liikkeellä. \\
\hline Syrjäyttää muussa tilanteessa & $\begin{array}{l}\text { Sonni pakottaa toisen sonnin luovuttamaan paikkansa muussa kuin ruokailutilanteessa puskemalla tai voimakkaalla vartalon } \\
\text { liikkeellä. }\end{array}$ \\
\hline Ajaa ylös & Sonni ajaa toisen eläimen ylös makuulta (esimerkiksi puskemalla, työntämällä, hyppäämällä selkään). \\
\hline Hyppää selkään & Sonni hyppää toisen sonnin selkään mistä suunnasta tahansa samaan tapaan kuin normaalissa astumisessa. \\
\hline Sosiaalinen nuoleminen & Sonni koskettaa kielellään toisen eläimen vartaloa. \\
\hline
\end{tabular}


Tämä kyseinen suuri ryhmä erosi muista tutkimuksen ryhmistä siinä suhteessa, että karsinaa käytettiin jatkuvatäyttöisyys-periaatteella.

Myös eläintiheys vaikuttaa aggressiivisen käyttäytymisen määrään naudoilla. Lehmillä on raportoitu vähemmän agonistista käyttäytymistä laitumella kuin sisällä pihatossa (O'Connell ym. 1989, Miller ja Wood-Gush 1991). Kondo ym. (1989) havaitsivat 6-13 kuukauden ikäisillä hiehoilla ja härillä agonistisen käyttäytymisen vähentyvän tilan lisääntyessä (4,0-73,4 m²/eläin). Tilan lisääntyessä aggressiot vähenevät, koska toisten eläinten väistäminen helpottuu ja yksilötilan loukkaukset vähenevät (Wierenga 1983). Tutkimustiloillamme suurissa sonniryhmissä oli keskimäärin enemmän tilaa eläintä kohden $\left(4,4-8,8 \mathrm{~m}^{2}\right)$ kuin keskisuurissa ryhmissä $\left(3,0-3,7 \mathrm{~m}^{2}\right)$. Alhaisempi eläintiheys saattoi hyvinkin hillitä aggressiivisen käyttäytymisen määrää suurissa ryhmissä. Suurien ja keskisuurien ryhmien olosuhteet erosivat toisistaan myös lattiamateriaaliin suhteen. Lattian materiaalilla itsellään ei kuitenkaan ole havaittu olevan vaikutusta sonnien aggressiivisen käyttäytymisen määrään (esim. Andersen ym. 1991). Laidunnettaessa suuria eläinmääriä laajoilla laitumilla, nautojen on havaittu muodostavan pienempiä, noin 10-15 eläimen alaryhmiä vähentääkseen suuren ryhmän haittoja (Hinch ym. 1982, Phillips 1993). Tutkimuksessamme emme selvittäneet muodostuiko suurissa ryhmissä pienempiä alaryhmiä.

Tutkimustiloillamme oli havaittavissa suuntaus, että ruokailutilanteessa tapahtuvan puskemisen ja syrjäytysten osuus kaikista kontakteista oli suurempi keskisuurissa kuin suurissa ryhmissä (Kuva 2). Ruokailutilan vähentyessä ruokailutilanteeseen liittyvien aggressioiden ja häirinnän on havaittu lisääntyvän naudoilla (DeVries ym. 2004). Erityisesti alempiarvoiset eläimet kärsivät ruokailutilan vähäisyydestä (Fraser ja Broom 2002). Tutkimustiloillamme keskisuurissa ryhmissä oli kuitenkin eläintä kohden hieman enemmän ruokailutilaa $(50-58 \mathrm{~cm} / \mathrm{eläin})$ kuin suurissa ryhmissä $(25-46 \mathrm{~cm} / \mathrm{eläin})$. Näin ollen ruokailutilan määrä tuskin selittää suuntausta ruokailutilanteissa tapahtuneiden aggressioiden ja häirinnän suurempaan esiintyvyyteen keskisuurissa ryhmissä. Usein naudoilla on havaittavissa selkeä syömisaktiivisuuden lisääntyminen välittömästi rehun jaon jälkeen (Cozzi ja Gottardo 2005), jolloin voi esiintyä kilpailua syömistilasta. Ruokailutilanteeseen liittyvän häirinnän hillitsemiseksi onkin ryhmän koosta riippumatta tärkeää, että eläimillä jatkuvasti hyvälaatuista rehua saatavilla.
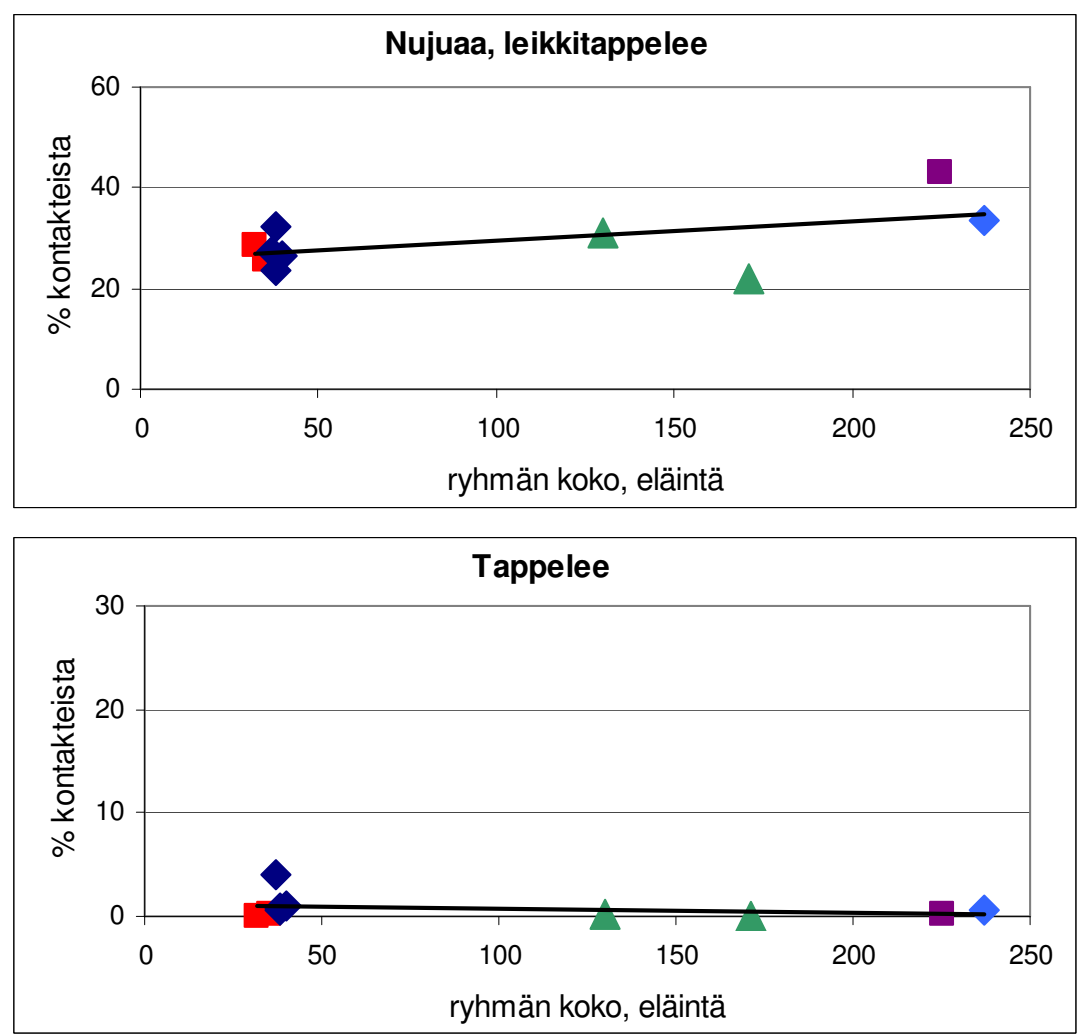

Kuva 1. Nujuamisen ja leikkitappelun sekä tappelun osuudet kaikista sosiaalisista kontakteista erikokoisissa sonniryhmissä. Samalla kuviolla merkityt sonniryhmät olivat samalta tilalta. 

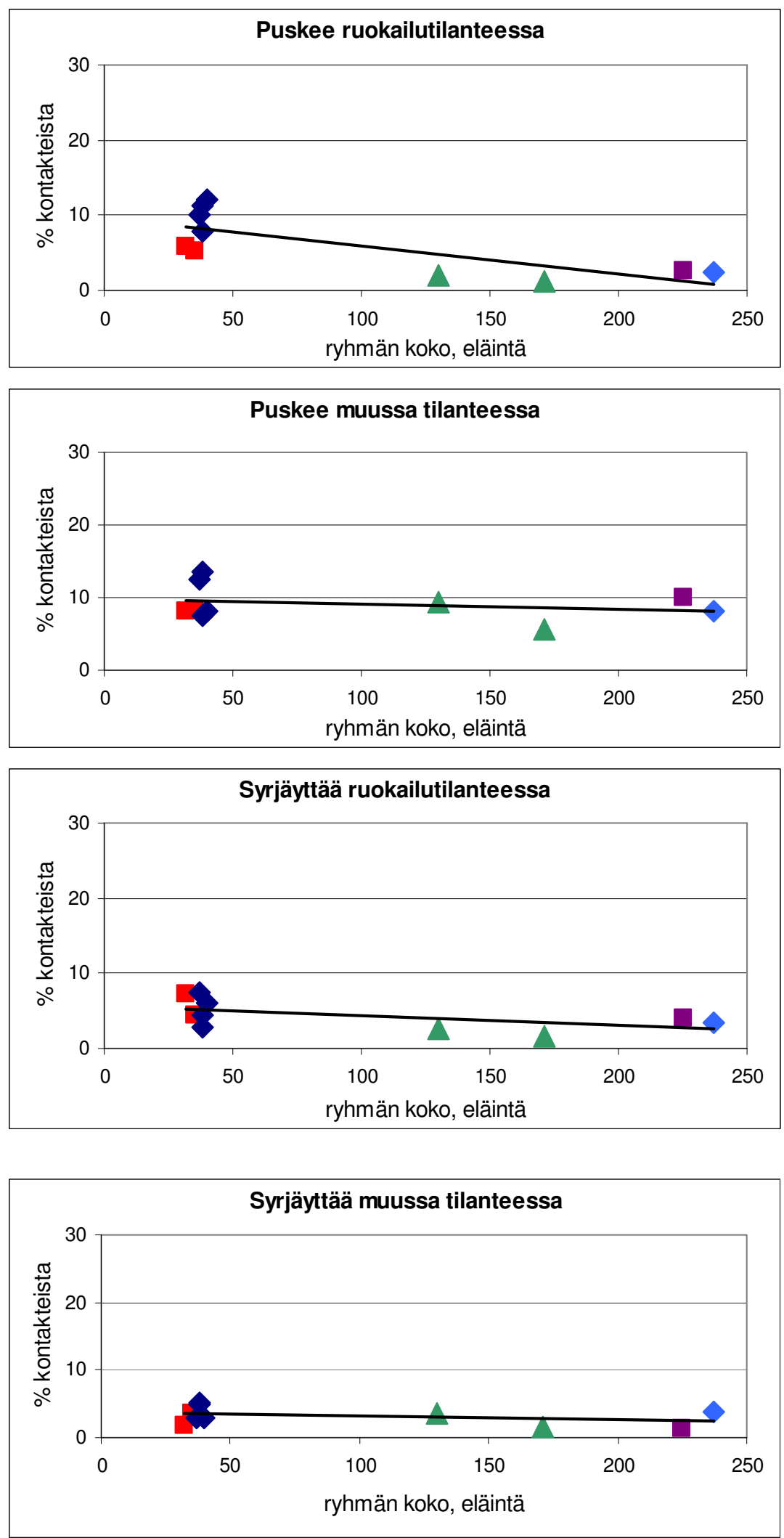

Kuva 2. Puskemisen ja syrjäyttämisen osuudet kaikista sosiaalisista kontakteista erikokoisissa sonniryhmissä. Samalla kuviolla merkityt sonniryhmät olivat samalta tilalta. 

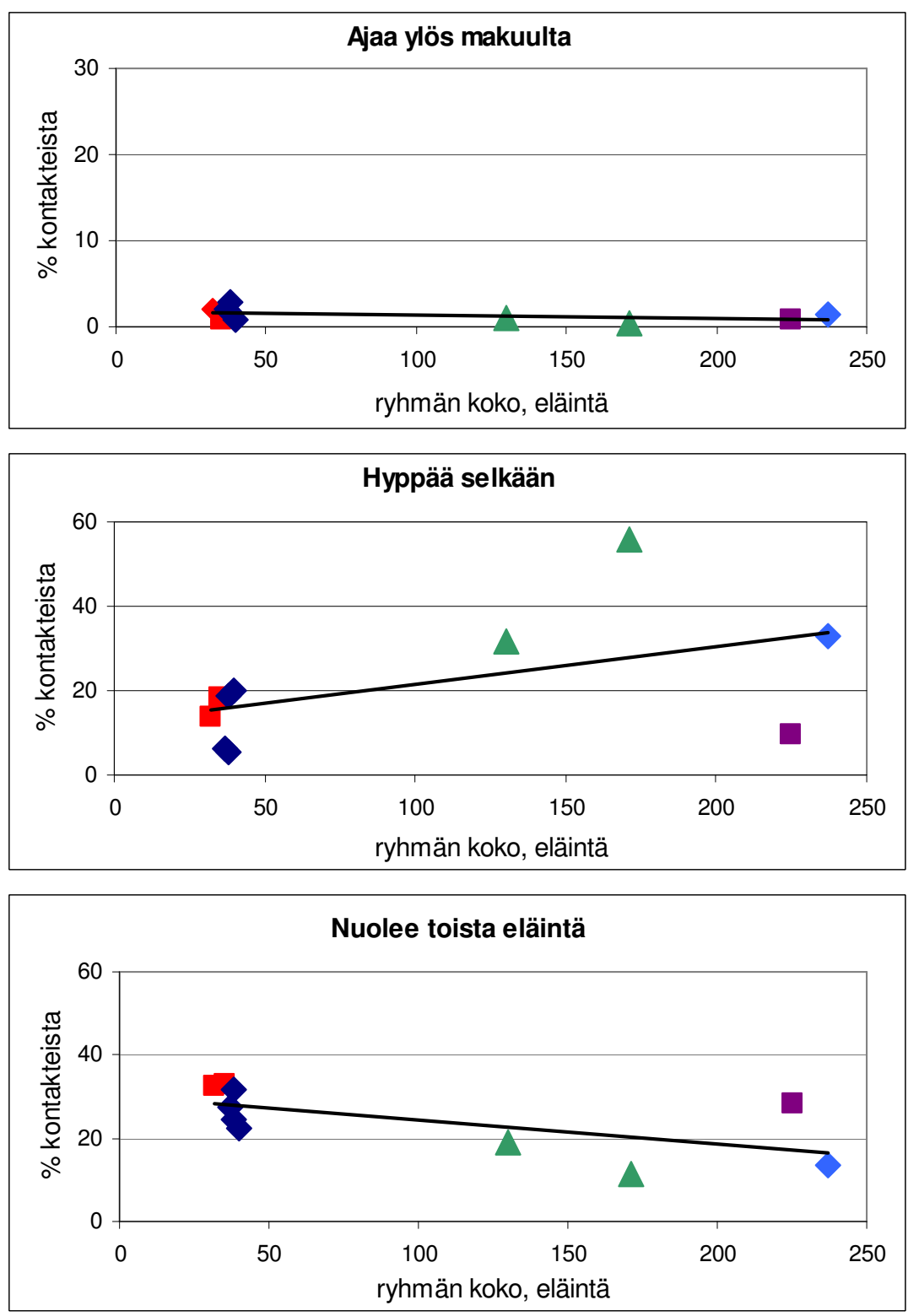

Kuva 3. Toisen eläimen makuulta ylös ajamisen, selkään hyppäämisen ja sosiaalisen nuolemisen osuudet kaikista sosiaalisista kontakteista erikokoisissa sonniryhmissä. Samalla kuviolla merkityt sonniryhmät olivat samalta tilalta.

Selkään hyppäämisen on havaittu kastroiduilla sonneilla lisääntyvän ryhmäkoon suurentuessa (Acosta ym. 1981). Tämän on arveltu olevan seurausta suuren ryhmän monimutkaisista sosiaalisista suhteista. Tutkimustiloillamme oli havaittavissa suuntaus, että toisen eläimen selkään hyppäämisen osuus kaikista kontakteista oli suurempi suurissa kuin keskisuurissa ryhmissä (Kuva 3). Suurissa ryhmissä hajonta oli kuitenkin huomattavaa. Selkään hyppäämistä esiintyi etenkin nuorista, 10-11 kk:n ikäisistä maitorotuisista sonneista koostuvassa ryhmässä. Härillä tietyt eläimet sallivat toisten eläinten toistuvasti hypätä selkäänsä, mistä voi seurata vakavia terveysongelmia (Acosta ym. 1981). Kuivitettu pohja tarjoaa eläimille pitävän pohjan, mikä ehkäisee liukastumisia hyppytilanteessa. Rakolattialla sonnit saattavat vältellä selkään hyppäämistä ilmeisestikin juuri liukastumisvaaran vuoksi (Andersen ym. 1991).

Sosiaalisella nuolemisella on eläinryhmässä jännitteitä vähentävä vaikutus ja se toimii myös sosiaalisten suhteiden lujittajana ja vakauttajana (Sato ym. 1993). Tutkimustiloillamme oli havaittavissa suuntaus, että sosiaalisen nuolemisen osuus kaikista kontakteista oli suurempi keskisuurissa kuin suurissa ryhmissä (Kuva 3). Usein naudat suosivat sosiaalisessa nuolemisessa sukulaisiaan tai tuttuja eläimiä, samanikäisiä eläimiä tai arvojärjestyksessä itseään lähellä olevia eläimiä (Wood 1977, Reinhard 1981, Sato ym. 1991). Keskisuurissa ryhmissä havaittu suuntaus sosiaalisen nuolemisen suurem- 
paan osuuteen kaikista kontakteista voi merkitä sitä, että eläimet pystyivät muodostamaan kiinteämpiä suhteita toisiinsa keskisuurissa kuin suurissa ryhmissä.

\section{Johtopäätökset}

Tilatutkimuksessamme emme havainneet, että suurissa, kiinteäpohjaisten karsinoiden sonniryhmissä (130-237 sonnia) aggressiivisen käyttäytymisen osuus kaikista sosiaalisista kontakteista olisi ollut suurempi kuin keskisuurissa, rakolattiakarsinoiden ryhmissä (32-40 sonnia). Ruokailutilanteeseen liittyvän häirinnän osuus kaikista kontakteista näytti kuitenkin olevan suurempi rakolattiakarsinoiden keskisuurissa ryhmissä kuin kiinteäpohjaisten karsinoiden suurissa ryhmissä. Suhteellisen alhainen eläintiheys saattoi hillitä aggressiivista käyttäytymistä suurissa ryhmissä. Sosiaalisen nuolemisen osuus kaikista kontakteista näytti olevan suurempi keskisuurissa kuin suurissa ryhmissä. Tämä voi merkitä sitä, että pienemmissä ryhmissä eläimet pystyivät muodostamaan kiinteämpiä suhteita toisiinsa. Tutkimuksemme aineisto oli hyvin pieni ja tulokset kuvailevia, joten johtopäätösten luotettavuuteen ja tulosten yleistettävyyteen on suhtauduttava varauksella.

\section{Kiitokset}

Kiitämme lämpimästi kaikkia tutkimukseen osallistuneita karjatiloja.

\section{Kirjallisuus}

Acosta, J. E., Shake, L. M., Brown, G. C. \& Vermedahl, L. D. 1981. Influence of implants, feed additives and pen size upon incidence of buller steers. Progress Report. Texas Agric. Exp. Stat. 3758/3830: 130-133.

Andersen, H. R., Krohn, C. C., Foldager, J., Munksgaard, L. \& Klastrup, S. 1991. Influence of housing and feeding on behaviour, feed intake, growth and carcass and meat quality. Beretning fra Statens Husdyrbrugsforsøg. No. 700. Denmark, Foulum: Statens Husdyrbrugsforsøg. 39 s.

Cozzi, G. \& Gottardo, F. 2005 Feeding behaviour and diet selection of finishing Limousin bulls under intensive rearing system. Appl. Anim. Behav. Sci. 91: 181-192.

DeVries, T. J., von Keyserlingk, M. A. G. \& Weary, D. M. 2004. Effect of feeding space on the inter-cow distance, aggression and feeding behaviour of free-stall housed lactating dairy cows. J. Dairy Sci. 87: 14321438 .

Fraser A.F. \& Broom. D.M. 2002. Farm animal behaviour and welfare. Kolmas painos. Wallingford: CAB International. $437 \mathrm{~s}$.

Hinch, G. N., Thwaites, C. J., Lynch, J. J. \& Pearson, A. J. 1982. Spatial relationships within a herd of young sterile bulls and steers. Appl. Anim. Ethol. 8: 27-44.

Kondo, S., Sekine, J., Okubo, M. \& Asahida, Y. 1989. The effect of group size and space allowance on the agonistic and spacing behavior of cattle. Appl. Anim. Behav. Sci. 24: 127-135.

Martin, P. \& Bateson, P. 1993. Measuring behaviour. An introductory guide. Toinen painos. UK: Cambridge University Press. 222 s.

Miller, K. \& Wood-Gush, D. G. M. 1991. Some effects of housing on the social behaviour of dairy cows. Anim. Prod. 53: 271-278.

O’Connell, J., Giller, P. S. \& Meaney, W. 1989. A comparison of dairy cattle behavioural patterns at pasture and during confinement. Ir. J. Agric. Res. 28: 65-72.

Phillips, C. J. C. 1993: Cattle behaviour. United Kingdom: Farming press. 212 s.

Reinhardt, V. 1981. Cohesive relationships in a cattle herd (Bos indicus). Behaviour 81: 121-151.

Sato, S., Sako, S. \& Maeda, A. 1991. Social licking patterns in cattle (Bos taurus): influence of environmental and social factors. Appl. Anim. Behav. Sci. 32: 3-12.

Sato, S. Tarumizu, K. \& Hatae, K. 1993. The influence of social factors on allogrooming in cows. Appl. Anim. Behav. Sci. 38: 235-244.

Wierenga, H. K. 1983. The influence of the space for walking and lying in a cubicle system on the behaviour of dairy cattle. Teoksessa: Baxter, S. H., Baxter, M. R. \& MacCormack, J. A. D. (toim.), Farm animal housing and welfare. Seminar in the CEC Programme of Coordination of Research on Animal Welfare, Aberdeen, Scotland, July 28-30, 1982. Martinus Nijhoff: The Hague, Netherlands. s. 171-180

Wood, M.T. 1977. Social grooming patterns in two herds of monozygotic twin dairy cows. Anim. Behav. 25: $635-642$. 